\title{
Thermal Transformations of Organic Nitrogen Bases in Resin Components of Oils of Various Types
}

\author{
Natalia N. Gerasimova*, \\ Raisa S. Min and Tatyana A. Sagachenko \\ Institute of Petroleum Chemistry SB RAS \\ 4 Akademichesky, Tomsk, 634055, Russia
}

Received 25.12.2018, received in revised form 26.02.2019, accepted 02.05.2019

\begin{abstract}
The composition and the structure of organic nitrogen bases of resins of low-and high-resin oils are studied before and after thermal exposure $\left(450^{\circ} \mathrm{C}, 30\right.$ minutes, inert medium). It is found that most of the bases in all samples of resins under study are high-molecular compounds, but their content in thermolized resins is significantly lower. Thermally transformed bases are characterized by lower values of average molecular weights, minority and smaller sizes of structural blocks constituting their mean molecules. A decrease in the overall size of the structural blocks is mainly due to a decrease in the number of saturated cycles in the naphtheno-aromatic system and carbon atoms in alkyl substituents. According to GC-MS data, the bases of all the resins under study are represented by the same sets of alkyl derivatives of quinoline, benzoquinoline, dibenzoquinoline, and azapirene. Alkyl derivatives of thiophenoquinoline and benzothiophenoquinoline are present in the composition of bases of highsulfur oil resins in significant amounts. In all cases, the maximum in the distribution of identified compounds falls to alkyl benzoquinolines. The special feature of organic nitrogen bases of thermally transformed resins is a high content in alkylquinolines and alkylthiophenoquinolines, as well as a higher percentage of structures with a lower number of carbon atoms in alkyl substituents. Thus, the chemical nature of oils is not responsible for main patterns of thermal transformation of organic nitrogen bases in oil resins.
\end{abstract}

Keywords: resins, organic nitrogen bases, thermal transformations, content, composition.

Citation: Gerasimova N.N., Min R.S., Sagachenko T.A. Thermal transformations of organic nitrogen bases in resin components of oils of various types, J. Sib. Fed. Univ. Chem., 2019, 12(2), 231-239. DOI: 10.17516/1998-2836-0121.

(c) Siberian Federal University. All rights reserved

* Corresponding author E-mail address: dm@ipc.tsc.ru 


\title{
Термические превращения \\ азоторганических оснований \\ смолистых компонентов нефтей различных типов
}

\author{
Н.Н. Герасимова, Р.С. Мин, Т.А. Сагаченко \\ Институт химии нефти СО РАН \\ Россия, 634055, Томск, пр. Академический, 4
}

Изучены состав и структура азоторганических оснований смол малосмолистой $u$ высокосмолистых нефтейдо и послетермического воздействия $\left(450^{\circ} \mathrm{C}, 30\right.$ мин, инертная среда). Установлено, что большую часть оснований во всех исследуемых образиах смол составляют высокомолекулярные соединения, однако их доля в термолизованных смолах существенно ниже. Термопреобразованные основания характеризуются меньшими значениями средних молекулярных масс, меньшим числом и меньшими размерами структурных блоков, входящих в состав их средних молекул. Уменьшение общих размеров структурных блоков происходит в основном за счет снижения числа насыщенных ииклов в нафтеноароматической системе и количества углеродных атомов в алкильном обрамлении. По данным ГХ-МС, основания всех исследуемых смол представлены сходными наборами алкилпроизводных хинолина, бензохинолина, дибензохинолина и азапирена. В составе оснований смол высокосернистых нефтей в заметном количестве присутствуют алкилпроизводные тиофенохинолина и бензотиофенохинолина. Во всех случаях максимум в распределении идентифицированных соединений приходится на алкилбензохинолины. Особенностью азоторганических оснований термопреобразованных смол является повыменное содержание алкилхинолинов и алкилтиофенохинолинов, а также более высокая доля в их составе структур с меньшим числом атомов углерода в алкильных заместителях. Таким образом, основные направления термического преобразования азоторганических оснований смол не зависят от химической природы нефти.

Ключевые слова: смолы, азоторганические основания, термические превращения, содержание, состав.

\section{Введение}

Смолы, составляющие значительную часть нефтяного сырья, считаются перспективным резервом углубления его переработки. В связи с этим накопление и обобщение данных о поведении смолистых компонентов разных по составу нефтей в процессе термического воздействия имеют большое значение для выбора оптимальных технологий их переработки. Особый интерес представляет информация об азоторганических основаниях (АО) смол, оказывающих негативное влияние на процессы каталитического облагораживания нефтяных фракций, качество и эксплуатационные характеристики горюче-смазочных материалов, окружающую среду и здоровье человека [1-5]. Сейчас сведения о структурных изменениях АО под воздействием температуры касаются главным образом их устойчивости в процессах гидроочистки дистил-

$$
-232-
$$


лятных фракций $[6,7]$ и моделирования процессов термического созревания для решения проблем геохимии $[8,9]$. Информация о поведении в процессах термолиза АО высокомолекулярных компонентов нефтей отсутствует. Актуальность сравнительного изучения особенностей термических превращений АО смол различных нефтей обусловлена неуклонным ростом в составе сырья, поступающего на НПЗ страны, доли тяжелых нефтей, которые характеризуются высоким содержанием гетероорганических соединений.

В работе представлены результаты изучения состава и структуры АО, выделенных из смол малосмолистой и высокосмолистых нефтей до и после термообработки, анализ которых позволил выявить сходства и различия в направлениях термических преобразований АО смолистых компонентов нефтей различных типов.

\section{Экспериментальная часть}

Использованные в работе малосмолистая и высокосмолистые нефти различаются по химическому типу, плотности, содержанию серы $(\mathrm{S})$, общего $(\mathrm{N})$ и основного азота $\left(\mathrm{N}_{\text {осн. }}\right)$ (табл. 1).

Смолы выделяли из деасфальтенизированных нефтей методом жидкостно-адсорбционной хроматографии на активированном силикагеле АСК с использованием в качестве десорбента смеси бензола с этанолом (50:50 по объему) после предварительного извлечения компонентов масел смесью гексана с бензолом в объемном отношении 70:30 [10].

Термолиз смол проводили при $450^{\circ} \mathrm{C}$ в течение 30 мин в инертной среде. При термической обработке смол образуются газообразные, твердые и жидкие продукты. Жидкие продукты разделяли на асфальтены (7,5, 23,4 и 17,1 \% мас.) и мальтены $(92,5,76,6$ и 82,9 \% мас. для смол нефтей I, II и III типов соответственно) по методике [10].

АО выделяли из гексановых растворов исходных смол и мальтенов по трехстадийной схеме [11], позволяющей разделять их на фракции: 1) стадия осаждения высокомолекулярных оснований газообразным хлористым водородом (образцы К-1), 2) стадия доосаждения растворимых в углеводородной среде хлористоводородных солей высокомолекулярных АО с помощью диэтиламина (образцы К-2) и 3) стадия экстракции низкомолекулярных АО уксуснокислым раствором серной кислоты (образцы К-3). Высокомолекулярные основания К-2, образующие растворимые комплексные соли, отличаются от высокомолекулярных оснований К-1 большим количеством нафтеновых и/или алкильных структурных фрагментов [12]. Образцы К-1 дополнительно разделяли методом горячей экстракции н-гексаном на растворимые $\left(К-1_{\text {гр }}\right)$ и нерастворимые (К-1 гнр) компоненты [11].

Таблица 1. Физико-химические характеристики нефтей

Table 1. Physical and chemical characteristics of oils

\begin{tabular}{|c|c|c|c|c|c|}
\hline \multirow{2}{*}{ Тип нефти } & \multirow{2}{*}{ 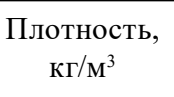 } & \multicolumn{4}{|c|}{ Содержание, \% мас. } \\
\hline & & Смолы & $\mathrm{S}$ & $\mathrm{N}$ & $\mathrm{N}_{\mathrm{ocH}}$ \\
\hline Метано-нафтеновая (I) & 867,0 & 8,8 & 1,05 & 0,35 & 0,03 \\
\hline Нафтено-метановая (II) & 978,0 & 18,4 & 3,89 & 0,67 & 0,12 \\
\hline Нафтеновая (III) & 971,5 & 22,1 & 1,97 & 0,64 & 0,19 \\
\hline
\end{tabular}


Для характеристики полученных концентратов и продуктов их разделения использовали элементный и функциональный анализы, определение средних молекулярных масс (МM), ЯМР-Фурье-спектроскопию, структурно-групповой анализ (СГА) и газовую хромато-массспектрометрию (ГХ-МС).

Элементный состав образцов определяли на автоматическом анализаторе C, H, S, N «Vario EL Cube». Содержание кислорода оценивали по разности между 100 \% и суммарным содержанием элементов: C, H, N, S. Функциональный анализ азоторганических соединений проводили методом неводного потенциометрического титрования [13]. ММ измеряли методом криоскопии в бензоле [10].

Спектры ЯMP ${ }^{1} \mathrm{H}$ записывали на спектрометре ЯMP-Фурье «AVANCE III HD (400 МГц)» фирмы «Bruker» при 400 МГц в растворах $\mathrm{CDCl}_{3}$. В качестве стандарта использовали тетраметилсилан. Относительное содержание протонов в различных структурных фрагментах определяли исходя из площадей сигналов в соответствующих областях спектра ЯМР ${ }^{1} \mathrm{H}: \mathrm{H}_{\mathrm{ar}}$ (доля протонов, содержащихся в ароматических структурах) $-6.6-8.5 \mathrm{ppm} ; \mathrm{H}_{\alpha}$ (доля протонов у атома углерода в $\alpha$-положении алифатических заместителей ароматических структур) - 2.2-4.0 ppm; $\mathrm{H}_{\beta}$ и $\mathrm{H}_{\gamma}$ (доля протонов в метиленовых и в концевых метильных группах алифатических фрагментов молекул) - 1.1-2.1 ppm и 0.3-1.1 ppm соответственно [14].

На основе данных о ММ, элементном составе и распределении протонов между различными фрагментами молекул рассчитывали средние структурные характеристики молекул АО [15]. В ходе расчетов определены следующие параметры: $m_{\mathrm{a}}$ - число структурных блоков в средней молекуле; $K_{0}^{*}, K_{a}^{*}, K_{н}^{*}-$ общее число, число ароматических и нафтеновых циклов в структурном блоке; $\mathrm{C}_{\text {п }}{ }^{*}$ - число атомов углерода в парафиновых фрагментах структурного блока; $\mathrm{C}_{\gamma}{ }^{*}$ - количество атомов углерода, находящихся в не связанных с ароматическими ядрами терминальных метильных группах.

ГХ-МС-анализ выполнен на приборе DFS фирмы «Thermo Scientific» при энергии ионизирующих электронов $70 \mathrm{eV}$, температуре ионизационной камеры $270{ }^{\circ} \mathrm{C}$, температуре интерфейca $270{ }^{\circ} \mathrm{C}$, температуре инжектора $250^{\circ} \mathrm{C}$. Для хроматографического разделения использовали колонку длиной 30 м, диаметром 0.25 мм, с толщиной фазы DB-5MS 0.25 мкм. Газ-носитель гелий при постоянном расходе - 0,8 мл/мин. Программа термостата: начальная температура $80{ }^{\circ} \mathrm{C}$ (3 мин), подъем до $300{ }^{\circ} \mathrm{C}\left(4{ }^{\circ} \mathrm{C} /\right.$ мин), выдержка при конечной температуре 30 мин. Сканирование масс-спектров осуществлялось каждую секунду в диапазоне масс до 500 а.е.м. Реконструкцию молекулярно-массового разделения (масс-хроматограмм) соединений проводили с применением характеристических ионов на основе хроматограмм по полному ионному току с помощью программы Xcalibur. Для идентификации индивидуальных соединений использовали компьютерную библиотеку масс-спектров NIST 02.

\section{Результаты и их обсуждение}

Сравнительный анализ показал, что концентрация $\mathrm{N}_{\text {осн. }}$ в мальтенах ниже, чем в исходных смолах (табл. 2). Это свидетельствует об участии АО смолистых веществ в формировании вторичных асфальтенов и твердых продуктов, образующихся при термолизе нефтяного сырья [8, 16-18]. Так, на долю $\mathrm{N}_{\text {осн. }}$ вторичных асфальтенов смол нефти II типа приходится около $21 \%$

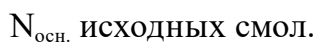


Natalia N. Gerasimova, Raisa S. Min... Thermal Transformations of Organic Nitrogen Bases in Resin Components of Oils...

Таблица 2. Содержание основного азота в исходных смолах (а) и мальтенах (б)

Table 2. Content of the main nitrogen in initial resin (a) and maltens (б)

\begin{tabular}{|c|c|c|c|c|c|c|}
\hline \multirow{3}{*}{ Показатель } & \multicolumn{6}{|c|}{ Смолы нефти } \\
\hline & \multicolumn{2}{|c|}{ I типа } & \multicolumn{2}{|c|}{ II типа } & \multicolumn{2}{|c|}{ III типа } \\
\hline & $\mathrm{a}$ & 6 & $\mathrm{a}$ & 6 & $\mathrm{a}$ & 6 \\
\hline Содержание $\mathrm{N}_{\text {осн. }}$ \% мас. & 0,25 & 0,14 & 0,44 & 0,31 & 0,55 & 0,23 \\
\hline
\end{tabular}

Таблица 3. Выделение и фракционирование азоторганических оснований исходных смол (а) и мальтенов (б)

Table 3. Isolation and separation of organic nitrogen bases of initial resin (a) and maltens (б)

\begin{tabular}{|c|c|c|c|c|c|}
\hline \multirow[t]{2}{*}{ Смолы нефти } & \multirow[t]{2}{*}{ Концентрат } & \multicolumn{2}{|c|}{$\begin{array}{c}\text { Содержание, } \\
\text { \% мас. }\end{array}$} & \multicolumn{2}{|c|}{ MM, а.е.м. } \\
\hline & & $\mathrm{a}$ & 6 & $\mathrm{a}$ & 6 \\
\hline \multirow{5}{*}{ I типа } & К-1, в т.ч.: & 10,9 & 8,7 & 1018 & 683 \\
\hline & $\mathrm{K}-1_{\Gamma \mathrm{P}}$ & 3,7 & 3,8 & 670 & 540 \\
\hline & $\mathrm{K}-1_{\text {ГНР }}$ & 7,2 & 4,9 & 1200 & 794 \\
\hline & K-2 & 13,2 & 0,3 & 607 & 413 \\
\hline & K-3 & 1,9 & 1,0 & 383 & 330 \\
\hline \multirow{5}{*}{ II типа } & К-1, в т.ч.: & 36,5 & 15,9 & 833 & 626 \\
\hline & $\mathrm{K}-1_{\Gamma \mathrm{P}}$ & 6,3 & 5,8 & 578 & 458 \\
\hline & K-1 $1_{\text {ГНР }}$ & 29,3 & 10,1 & 1072 & 920 \\
\hline & $\mathrm{K}-2$ & 0,6 & 6,4 & 636 & 507 \\
\hline & K-3 & 1,3 & 1,1 & 383 & 317 \\
\hline \multirow{5}{*}{ III типа } & К-1, в т.ч.: & 37,6 & 9,5 & 844 & 597 \\
\hline & $\mathrm{K}-1_{\Gamma \mathrm{P}}$ & 19,5 & 4,9 & 592 & 458 \\
\hline & $\mathrm{K}-1_{\text {ГНР }}$ & 18,1 & 4,6 & 1566 & 748 \\
\hline & K-2 & 2,2 & 0,9 & 519 & 412 \\
\hline & K-3 & 1,0 & 0,6 & 392 & 310 \\
\hline
\end{tabular}

Особенностью мальтенов нефтей различных типов является более низкое суммарное количество выделенных из них концентратов азотистых оснований К-1 - К-3 (табл. 3). Большую часть АО мальтенов и исходных смол составляют высокомолекулярные соединения К-1 и К-2. Однако в мальтенах их суммарное содержание существенно ниже, чем в исходных смолах. При этом термическим преобразованиям в смолах нефти I типа в большей степени подвергаются высокомолекулярные соединения К-2. В процессе термолиза смол их количество снижается с 13,2 до 0,3 \% мас. В составе АО смол нефтей II и III типов существенно уменьшается количество соединений К-1. Смолы этих нефтей различаются по поведению оснований К-2 при термолизе. В случае нефти II их содержание возрастает, а в случае нефти III - снижается. Выявленные отличия в направлениях термических превращений высокомолекулярных АО исследуемых смол, вероятнее всего, обусловлены структурными различиями этих соединений в молекулах смолистых компонентов нефтей разных химических типов. 
Для смол нефтей всех типов количество образующихся при термолизе низкомолекулярных АО (К-3) сопоставимо с их содержанием в исходных образцах (табл. 3).

Процесс термодеструкции сопровождается увеличением в составе высокомолекулярных оснований К-1 исследуемых смол доли гексанорастворимых продуктов (К $\left.1_{\text {гр }}\right)(43,7$, 36,5 и 52,1 против $33,9,17,7$ и 48,1 \% отн. для смол нефтей I, II и III типов соответственно).

Высоко- и низкомолекулярные АО мальтенов имеют меньшие средние молекулярные массы (МM), чем соответствующие продукты исходных смол (табл. 3). Снижение средних значений ММ может быть связано с изменением структуры высокомолекулярных (К-1) АО, обусловленным протеканием при термолизе реакций деалкилирования и отрыва и/или раскрытия нафтеновых циклов в их молекулах $[8,17]$.

Такое предположение согласуется с результатами СГА продуктов фракционирования высокомолекулярных соединений К-1, концентратов К-2 и К-3 исходных смол и мальтенов. На примере структурно-групповых параметров средних молекул соединений К-1 гнр показано, что средние молекулы АО мальтенов отличаются меньшим числом и меньшими размерами структурных блоков $\left(m_{\mathrm{a}}\right)$, входящих в их состав (табл. 4). Уменьшение общих размеров структурных блоков происходит в основном за счет снижения числа насыщенных циклов $\left(\mathrm{K}_{\mathrm{H}}^{*}\right)$ и количества углеродных атомов в алкильном обрамлении $\left(\mathrm{C}_{\text {п }}{ }^{*}\right)$. Среди последних наблюдается уменьшение числа атомов углерода в метильных группах, удаленных от ароматического ядра $\left(\mathrm{C}_{\gamma}{ }^{*}\right)$, что свидетельствует об уменьшении числа и/или степени разветвленности заместителей.

ГХ-МС-анализ продуктов К-1 Гр, К-2 и К-3 показал, что в составе АО исходных смол и мальтенов нефтей разных химических типов присутствуют сходные наборы алкилпроизводных хинолина (Х), бензохинолина (БХ), дибензохинолина (ДБХ) и азапирена (АП). В смолах высокосернистых нефтей II и III в заметном количестве присутствуют алкилпроизводные тиофенохинолина (ТХ) и бензотиофенохинолина (БТХ) (табл. 5). Во всех случаях максимум в распределении идентифицированных структур приходится на

Таблица 4. Расчетные структурные параметры средних молекул высокомолекулярных оснований К-1 исходных смол (а) и мальтенов (б)

Table 4. Calculated structural parameters of the molecules of of high-molecular bases $\mathrm{K}-1_{\mathrm{HNS}}$ of initial resin (a) and maltens (б)

\begin{tabular}{|c|c|c|c|c|c|c|}
\hline \multirow{3}{*}{ Параметры } & \multicolumn{6}{|c|}{ К- $1_{\text {гнр }}$ смол нефти } \\
\hline & \multicolumn{2}{|c|}{ I типа } & \multicolumn{2}{|c|}{ II типа } & \multicolumn{2}{|c|}{ III типа } \\
\hline & $\mathrm{a}$ & 6 & $\mathrm{a}$ & 6 & $\mathrm{a}$ & $\sigma$ \\
\hline$m_{\mathrm{a}}$ & 2,7 & 2,1 & 2,3 & 2,1 & 3,0 & 2,1 \\
\hline $\mathrm{K}_{\mathrm{o}}^{*}$ & 6,8 & 6,2 & 10,0 & 9,2 & 7,9 & 4,8 \\
\hline $\mathrm{K}_{\mathrm{a}}^{*}$ & 3,0 & 2,8 & 2,8 & 2,7 & 2,9 & 2,8 \\
\hline $\mathrm{K}_{\mathrm{H}} *$ & 3,8 & 3,4 & 7,2 & 6,5 & 5,0 & 2,0 \\
\hline $\mathrm{C}_{\mathrm{n}}{ }^{*}$ & 3,7 & 1,4 & 2,2 & 1,9 & 7,5 & 4,3 \\
\hline $\mathrm{C}_{\gamma}{ }^{*}$ & 1,6 & 1,4 & 2,2 & 1,9 & 2,4 & 1,3 \\
\hline
\end{tabular}


Таблица 5. Состав азоторганических оснований исходных смол и мальтенов

Table 5. Composition of organic nitrogen bases of initial resin and maltens

\begin{tabular}{|l|c|c|c|c|c|c|}
\hline \multirow{2}{*}{ Соединения } & \multicolumn{3}{|c|}{ Содержание, \% относительно идентифицированных структур } \\
\cline { 2 - 7 } & \multicolumn{3}{|c|}{ Смолы исходные } & \multicolumn{3}{c|}{ Мальтены } \\
\cline { 2 - 8 } & $\begin{array}{c}\text { Нефть } \\
\text { I типа }\end{array}$ & $\begin{array}{c}\text { Нефть } \\
\text { II типа }\end{array}$ & $\begin{array}{c}\text { Нефть } \\
\text { III типа }\end{array}$ & $\begin{array}{c}\text { Нефть } \\
\text { I типа }\end{array}$ & $\begin{array}{c}\text { Нефть } \\
\text { II типа }\end{array}$ & $\begin{array}{c}\text { Нефть } \\
\text { III типа }\end{array}$ \\
\hline Алкилхинолины & 1,5 & 0,1 & 0,1 & 4,5 & 18,8 & 24,2 \\
\hline Алкилбензохинолины & 87,0 & 68,5 & 94,7 & 88,1 & 45,2 & 65,7 \\
\hline Алкилдибензохинолины & 9,1 & 1,7 & 1,2 & 1,6 & 0,6 & 0,7 \\
\hline Алкилазапирены & 2,5 & 6,0 & 3,8 & 5,8 & 2,7 & 5,7 \\
\hline Алкилтиофенохинолины & - & 22,4 & 0,2 & - & 32,7 & 3,4 \\
\hline Алкилбензотиофенохинолины & - & 1,3 & следы & - & 0,1 & - \\
\hline
\end{tabular}

алкилбензохинолины. Особенностью АО мальтенов всех нефтей является повышенное относительное содержание менее циклических структур - алкилхинолинов и алкилтиофенохинолинов.

Для термопреобразованных АО характерна также более высокая доля в их составе структур с меньшим числом атомов углерода в алкильных заместителях.

\section{Заключение}

В результате сравнительного изучения состава и структуры АО смол высоко- и малосмолистых нефтей до и после термообработки показано, что основные направления термического преобразования АО не зависят от химической природы нефти. АО исходных и термопреобразованных смол представлены высоко- и низкомолекулярными соединениями с преобладанием высокомолекулярных компонентов, доля которых в мальтенах существенно ниже. Отличительными чертами АО мальтенов являются меньшие значения средних молекулярных масс, меньшие размеры средних молекул и повышенная степень их ароматичности. АО мальтенов и исходных смол характеризуются одинаковым набором алкилпроизводных хинолина, бензохинолина, дибензохинолина и азапирена с максимальным содержанием алкилбензохинолинов. В составе АО высокосмолистых высокосеренистых нефтей также присутствуют азотсерусодержащие соединения, представленные алкилпроизводными тиофенохинолина и бензотиофенохинолина. Особенность АО мальтенов - повышенное относительное содержание алкилхинолинов и алкилтиофенохинолинов и структур с меньшим числом атомов углерода в алкильных заместителях.

\section{Список литературы}

1. Prado G.H.C., Rao Y., de Klerk A. Nitrogen Removal from Oil: A Review. Energy and Fuels. 2017. Vol. 31. No. 1, P. 14-36.

2. Liu M., Zhang L.Z., Zhang C., Yuan S.H., Duan L.H. Transformation of nitrogen-containing compounds in atmospheric residue by hydrotreating. Korean Jounal of Chemical Engineering. 2018. Vol. 35. No. 2, P. 375-382.

$$
-237-
$$


3. Chen X., Liu Y., Li S., Feng X., Shan H., Yang C. Structure and Composition Changes of Nitrogen Compounds during the Catalytic Crecking Process and Their Deactivating Effect on Catalysts. Energy and Fuels. 2017. Vol. 31. No. 4, P. 3659-3668.

4. Kong J., Wei X.Y., Yan H.L., Li Z.K., Zhao M.X., Li Y., Zong Z.M. Analysis of extractable basic nitrogen compounds in Buliangou subbituminous coal by positive-ion ESI FT-ICR MS. Fuel. 2015. Vol. 159, P. 385-391.

5. Zhang J., Shan H., Chen X., Liu W., Yang Ch. Synergistic Process for High Nitrogen Content Feedstocks Catalytic-Cracking: A Case Study of Controlling the Reactions of Nitrogen Compounds in Situ. Industrial and Engineering Chemistry Research. 2014. Vol. 53. No. 14, P. 5718-5727.

6. Chen X., Li T., Xin L., Yang Y., Shan H., Yang C. Inductive effect of basic nitrogen compounds on coke formation during the catalytic cracking process. Catalysis Communications. 2016. Vol. 74, P. 95-98.

7. Li S.J., Liu N.N. The transformation of basic nitrogen compounds in coker gas oil during catalytic cracking. Petroleum Science and Technology. 2017. Vol. 35. No. 11, P. 1141-1145.

8. Zhang Y., Liao Y., Guo S., Xu C., Shi Q. Molecular Transformation of Crude Oil in Confined Pyrolysis System and its Impact on Migration and Maturity Geochemical Parameters. Energy and Fuels. 2016. Vol. 30. No. 9, P. 6923-6932.

9. Rocha Y.D., Pereira R.C.L., Mendonca J.G. Negative electrospray Fourier transform ion cyclotron resonance mass spectrometry determination of the effects on the distribution of acids and nitrogen containing compounds in the simulated thermal evolution of a Type I source rock. Organic Geochemistry. 2018. Vol. 115, P. 32-45.

10. Современные методы исследования нефтей (справочно-методическое пособие). Под ред. Богомолова А.И., Темянко М.Б., Хотынцевой. Л.: Недра, 1984. 431 с. [Modern methods of a research of oils: reference benefit. Handbook. Under Ed. Bogomolova A.I., Temyanko M.B., Khotyntsevoy L.I. Leningrad: Nedra, 1984, 431 p. (In Russ.)]

11. Cheshkova T.V., Gerasimova N.N., Sagachenko T.A., Min R.S. Chemical composition of petroleum from Krapivinskoe oilfield (message 4). Bulletin of the Tomsk Polytechnic University, Geo Assets Engineering 2017. Vol. 328. No. 8, P. 6-15.

12. Химический состав нефтей Западной Сибири. Под ред. Г.Ф. Большакова. Новосибирск: Наука, 1988. 288 с. [Chemical composition of oils of Western Siberia Handbook. Under Ed. G.F. Bolshakova. Novosibirsk: Nauka, 1988. 288 p. (In Russ.)]

13. Okuno I., Latham D.R., Haines W.E. Type Analisis of Nitrogen in Petroleum Using Nonaqueous Potentiometric Titration and Litium Aluminum Hydride Reduction. Analitical Chemistry. 1965. Vol. 37. No. 1, P. 54-57.

14. Fergoug T., Bouhadda Y. Determination of Hassi Messaoud asphaltene aromatic structure from H-1 \& C-13 NMR analysis. Fuel. 2014. Vol. 115. No. 1, P. 521-526.

15. Golovko A.K., Kam'yanov V.F., Ogorodnikov V.D. High-molecular heteroatomic components of crude oils of the Timan-Pechora petroliferous basin. Russian Geology and Geophysics. 2012. Vol. 53. No. 12, P. 1374-1381.

16. Alshareef A.N., Scherer A., Stryker J.M., Gray M.R. Thermal cracking of substituted cholestane-benzoquinoline asphaltene model compounds (Conference Paper). Energy Fuels. 2012. Vol. 26. No. 6, P. 3592-3603. 
17. Speight Jg. Thermal transformations of asphaltenes. Petroleum Chemistry. 1989. Vol. 29. No. 4, P. 253-261.

18. Антипенко В.Р. Термические превращения высокосернистого природного асфальтита: Геохимические и технологические аспекты. Новосибирск: Наука, 2013. 184 с. [Antipenko V.R. Thermal transformations of a sulphur-rich natural asphaltite: Geochemical and technological aspects. Novosibirsk: Nauka, 2013, 184 p. (In Russ.)]. 